9

\title{
Long-term outcomes and management of the heart transplant recipient
}

\author{
Sharon L. McCartney, MD, Assistant Professor of \\ Anesthesiology ${ }^{\mathrm{a}, 1}$, \\ Chetan Patel, MD, Associate Professor of Anesthesiology b, *, \\ J. Mauricio Del Rio, MD, Assistant Professor of \\ Anesthesiology ${ }^{\mathrm{a}, 1}$

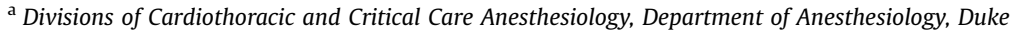 \\ University Medical Center, Durham, NC, USA \\ b Division of Cardiology, Department of Internal Medicine, Duke University Medical Center, Durham, \\ NC, USA
}

\section{Keywords:}

heart transplantation

transplants

transplantation

complications

graft rejection

immunosuppression

outcomes
Cardiac transplantation remains the gold standard in the treatment of advanced heart failure. With advances in immunosuppression, long-term outcomes continue to improve despite older and higher risk recipients. The median survival of the adult after heart transplantation is currently 10.7 years. While early graft failure and multiorgan system dysfunction are the most important causes of early mortality, malignancy, rejection, infection, and cardiac allograft vasculopathy contribute to late mortality. Chronic renal dysfunction is common after heart transplantation and occurs in up to $68 \%$ of patients by year 10 , with $6.2 \%$ of patients requiring dialysis and $3.7 \%$ undergoing renal transplant. Functional outcomes after heart transplantation remain an area for improvement, with only $26 \%$ of patients working at 1 -year posttransplantation, and are likely related to the high incidence of depression after cardiac transplantation. Areas of future research include understanding and managing primary graft dysfunction and reducing immunosuppression-related complications.

(C) 2017 Elsevier Ltd. All rights reserved.

\footnotetext{
* Corresponding author. Fax: +19196132389.

E-mail addresses: Sharon.McCartney@duke.edu (S.L. McCartney), Chetan.Patel@duke.edu (C. Patel), jm.delrio@duke.edu (J.M. Del Rio).

1 Fax: +19196818994.
} 


\section{Contemporary outcomes in heart transplantation}

Despite recent advances in mechanical circulatory support, heart transplantation remains the treatment of choice for patients with advanced heart failure. For such patients, there is a marked improvement in survival, quality of life, and functional status [1]. During the past 30 years, there has been a continuous improvement in morbidity and mortality despite older and higher risk recipients receiving transplant [2-4]. However, graft failure, rejection, and infection remain considerable causes of morbidity and mortality, precluding better outcomes in both the short and long term.

Since 1980, the volume of heart transplants has risen, with 4157 adult heart transplants being performed worldwide from 2014 to 2015 [4]. The median survival of adult heart transplant recipients is currently 10.7 years, with $82 \%$ 1-year survival and 69\% at 5 years [4], and slightly better survival for women $[3,4]$. The highest incidence of mortality occurs in the first 6 months post-transplant, with the perioperative hospitalization carrying the highest risk of death among any other period [4,5]. After the first year, the mortality rate decreases to $3.4 \%$ per year. Therefore, a more accurate description of survival is provided by the conditional median survival-the time point at which $50 \%$ of patients who survived the first year are still alive, which is 13.3 years for adult transplant recipients [4]. There is a trend for a significant increase in the proportion of patients aged >60 years old receiving heart transplant within the last decade. This is important because survival is affected by recipient and donor age. Therefore, considering the proportion of older and higher risk recipients, the continued improvement in survival is important [4]. With the improvement in survival, the frequency of retransplantation has remained constant over time at $2-4 \%$ [2].

In the past, recipients undergoing left ventricular assist device (LVAD) support as a bridge to transplant had a poor prognosis. However, during 2009-2013, the survival for patients supported by LVAD was comparable to those receiving inotropes only (Fig. 1) [4]. This is of major significance because currently $42 \%$ of patients undergoing transplant are bridged to transplant with LVAD support [4]. On the other hand, patients undergoing extracorporeal membrane oxygenation (ECMO) support at the time of transplant have significantly higher mortality (Fig. 1) [4]. Other important independent risk factors for mortality at 1 year are the pretransplant use of temporary mechanical circulatory support (in particular right ventricular assist device), mechanical ventilation, congenital, ischemic and restrictive cardiomyopathies, and re-transplantation. Such risk factors reflect the impact of pretransplant disease severity and organ function in early survival [3,4].

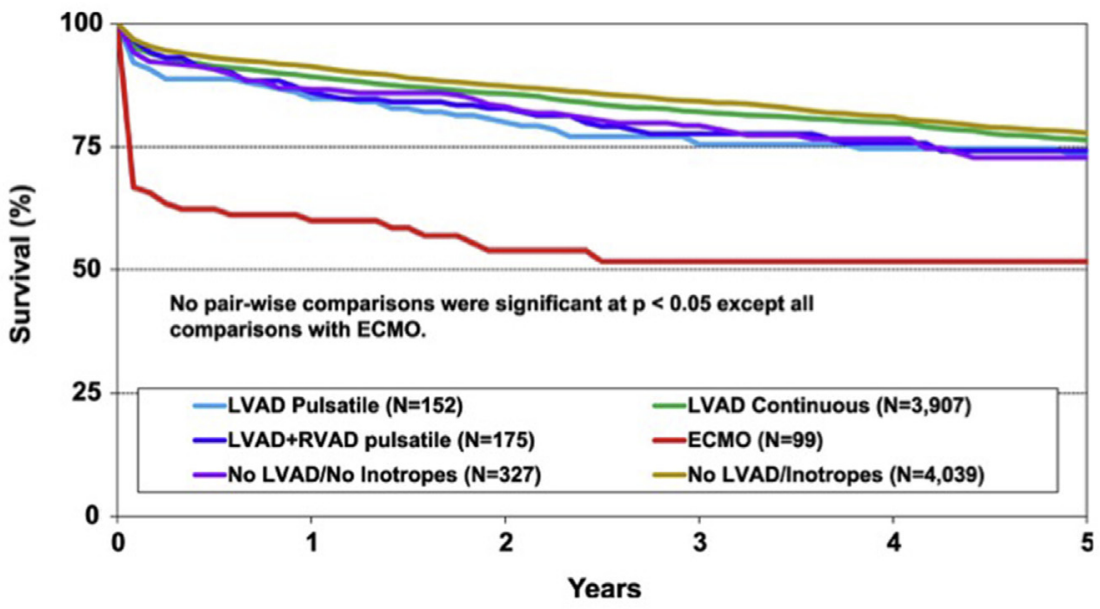

Fig. 1. Survival after heart transplant. Kaplan-Meier curves showing intermediate term survival by pretransplant mechanical circulatory support device. Reprinted from J Heart Lung Transplant 35 (10), Lund et al. The Registry of the International Society for Heart and Lung Transplantation: Thirty-third Adult Heart Transplantation Report - 2016: Focus Theme: Primary Diagnostic Indications for Transplant, 1158-1169, 2016, with permission from Elsevier. 


\section{Important outcomes by organ system}

\section{Neurologic}

Neurologic complications affect $10-30 \%$ of patients after heart transplantation and lead to increased mortality and decreased functional outcome, with $20 \%$ of deaths attributable to neurologic complications [6-8]. While neurologic sequelae after heart transplantation are similar to the spectrum of complications after cardiac surgery, the incidence is higher and some neurologic complications remain unique to patients undergoing transplantation.

The rate of cerebrovascular accident (CVA) after heart transplant is reported up to 13\% [6,8-11], and is associated with increased mortality post-transplant [6]. CVAs can be defined as either ischemic or hemorrhagic, with ischemic CVAs being twice as common as hemorrhagic CVAs after heart transplantation [6]. Risk factors for ischemic stroke include a preoperative history of hypertension, diabetes mellitus, smoking, and stroke, which are classic risk factors for stroke after cardiac surgery. Some risk factors that are unique to cardiac transplantation include a history of LVAD, intra-aortic balloon pump (IABP), prolonged cardiopulmonary bypass (CPB) time, and postoperative hepatic failure [12]. Symptomatic cerebrovascular disease increases the risk of ischemic CVA fourfold after cardiac transplantation [9]. The clinical manifestations of ischemic stroke vary depending on the territory of the occlusion. Occlusion of the anterior circulation is most common in heart transplant recipients, with total and partial occlusion of the anterior circulation found in $23.1 \%$ and $38.4 \%$ of patients, respectively [13]. Early hemorrhagic CVAs may be related to a relative hyperperfusion after heart transplantation compared to the low cardiac output pretransplant as cerebral blood flow may increase up to $50 \%$ after heart transplantation [14,15]. Whether ischemic or hemorrhagic, postoperative CVA remains an important complication and is associated with increased mortality after heart transplantation [6].

One of the most common complications in the perioperative period is delirium and/or encephalopathy, occurring in approximately $9 \%$ of patients [6,8]. The incidence subsequently declines after the perioperative period. Posterior reversible encephalopathy syndrome (PRES) occurs in patients after transplantation and treatment with calcineurin inhibitors and is characterized by encephalopathy, headache, visual disturbances, and seizures. MRI of the brain typically demonstrates the involvement of the occipito-parietal lobes. The pathophysiology of PRES remains unclear but occurs in approximately $1 \%$ of patients after heart transplantation $[6,8]$. Symptoms of PRES are typically reversible after altering the immunosuppressive regimen.

Polyneuropathies may occur after cardiac transplantation. In one small study, it was found that $30 \%$ of heart transplant candidates have a polyneuropathy prior to transplant, which may be explained by concomitant metabolic disorders such as diabetes and chronic kidney disease (CKD), in addition to critical illness polyneuropathy related to prior intensive care unit (ICU) admissions [16]. After heart transplantation, the rate of polyneuropathy increases to 70\% [16]. Sepsis, prolonged mechanical ventilation, and prolonged ICU stay predispose heart transplant recipients to neuromuscular disease postoperatively. Signs of critical illness polyneuropathy may last for up to 5 years after ICU discharge [17].

While delirium and CVAs are the most common neurologic complications in the perioperative period, pain and depression are the most common long-term neurologic sequelae and occur in 15-37\% of patients $[6,8,18]$. Impairments in physical, psychological, social, and environmental quality of life post transplantation affect the incidence of post-transplant depression. Social support is an important factor for the psychological well-being of heart transplant recipient before and after heart transplantation [19].

\section{Respiratory}

Patients with advanced heart failure have considerable changes in pulmonary function, including abnormal pulmonary diffusion, evident by decreased diffusing capacity of the lungs for carbon monoxide [20]. Gas exchange impairment persists in $67 \%$ of patients after transplantation, independent of smoking status, prior drug use, chest radiographic changes, hemodynamic findings, or duration of heart failure [21]; however, pulmonary function test results may improve in some patients 1 year after 
transplantation [22]. Abnormal pulmonary gas exchange limits exercise capacity [23] and can result in exercise-induced hypoxemia [24]. Exercise intolerance in heart transplant recipients is not only caused by gas exchange abnormalities but also by multiple cardiac, vascular, skeletal muscle, and neurohormonal alterations [25].

\section{Cardiovascular}

Graft failure and primary graft dysfunction

Graft failure is the most common cause of short-term mortality after heart transplantation (Fig. 2) $[4,26]$. Early graft failure (EGF), defined as a composite of death and/or re-transplantation associated with graft failure during the first 30 days after transplant, is the most severe form of primary graft dysfunction (PGD) and constitutes the most feared complication. The incidence of EGF reported for transplants performed between 2005 and 2013 was 3.8\%, with a 96.3\% mortality rate and 3.6\% requiring re-transplantation [3]. Risk factors for EGF include increased donor age, nonhead trauma as the donor cause of death, prolonged graft ischemic time, male recipient of female donor, recipient amiodarone use, donor cigarette history, recipient high pulmonary vascular resistance, recipient high serum creatinine, and recipient use of dialysis, mechanical ventilation, IABP, or mechanical circulatory support $[3,26]$. This highlights the probable synergistic effect that diverse donor and recipient factors have in the occurrence of EGF.

Graft dysfunction is classified as primary when there are no recognizable causal influences or secondary when factors such as hyperacute rejection, sepsis, and right ventricular dysfunction are identified. According to the "Report from a consensus conference on primary graft dysfunction after cardiac transplantation" published in 2014, 66\% of early deaths reported are due to graft failure and/or multisystem organ failure. However, it is probable that PGD causes most instances of early multisystem organ failure. Thus, the latter would not constitute a separate complication in itself [3,27]. The PGD consensus reported an incidence ranging from $2.3 \%$ to $28.2 \%$ [27]. Overall PGD mortality in transplant recipients between 1982 and 2011 was approximately $10 \%$ and $14 \%$ at 30 and 90 days post-transplant, respectively [27]. PGD mortality varies by the cause of end-stage heart disease, with congenital heart disease and valvular cardiomyopathy having the highest 30 -day mortality (15\% and $12 \%$, respectively) [27].

Although the pathogenesis of PGD is not completely elucidated yet, the most important donordependent risk factors are donor age, cause of death (i.e., brain death), female donor to male

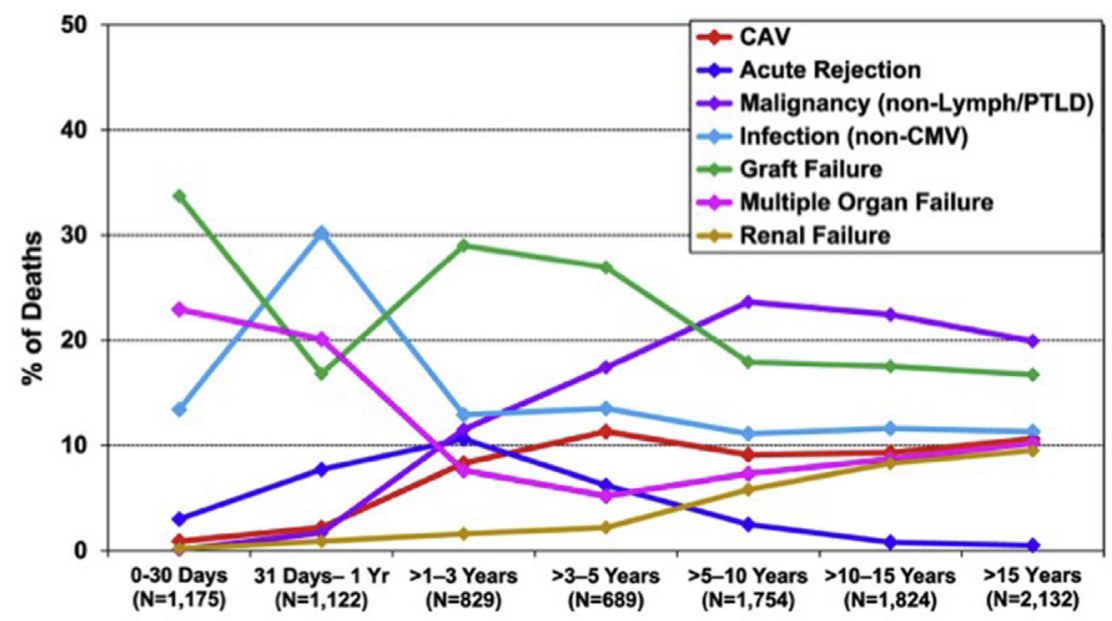

Fig. 2. Causes of death after heart transplant. Causes of death by duration after transplant (CAV - Cardiac Allograft Vasculopathy). Reprinted from J Heart Lung Transplant 34 (10), Lund et al. The Registry of the International Society for Heart and Lung Transplantation: Thirty-second Adult Heart Transplantation Report - 2015: Focus Theme: Primary Diagnostic Indications for Transplant, 1244-1254, with permission from Elsevier. 
recipient transplant, presence of coronary artery disease and/or left ventricular hypertrophy, and the use of catecholamines at the time of death. With regard to the transplant recipient, the most important risk factors are age, presence of increased pulmonary vascular resistance, use of inotropes or mechanical circulatory support at time of transplantation, and re-transplantation. Procedural risk factors include donor organ ischemic time, donor-to-recipient size mismatch, prolonged CPB time, and high transfusion requirement [27]. In the presence of risk factors, the RADIAL score is a validated scoring system that assesses the risk of PDG (Table 1) [27,28].

The diagnosis of PGD should be made within $24 \mathrm{~h}$ of transplantation and because of the different treatment for left vs. right ventricular dysfunction, there must be a clear distinction. Table 2 details the classification for graft dysfunction, including grading criteria and severity.

Finally, the management of PGD is largely supportive and generally involves a combination of inotropes, IABP, and pulmonary vasodilators. If there is no response to escalating medical treatment, short-term mechanical circulatory support is warranted [29]. However, there is no clear protocol for the management of PGD, and institutional protocols vary. Available evidence suggests that early and short-term use of mechanical circulatory support (ECMO or VAD) is the only effective means to treat severe forms of PGD and can offer improved survival when compared with medical management $[27,30,31]$. In particular, a retrospective analysis of a single center large cohort suggests better outcomes for veno-arterial ECMO than for temporary VAD support [32].

\section{Cardiac allograft vasculopathy}

Cardiac allograft vasculopathy (CAV) is a progressive vascular occlusive disease affecting the coronary vessels of cardiac allografts after transplantation and remains an important morbidity after heart

\section{Table 1}

The radial score to predict primary graft dysfunction.

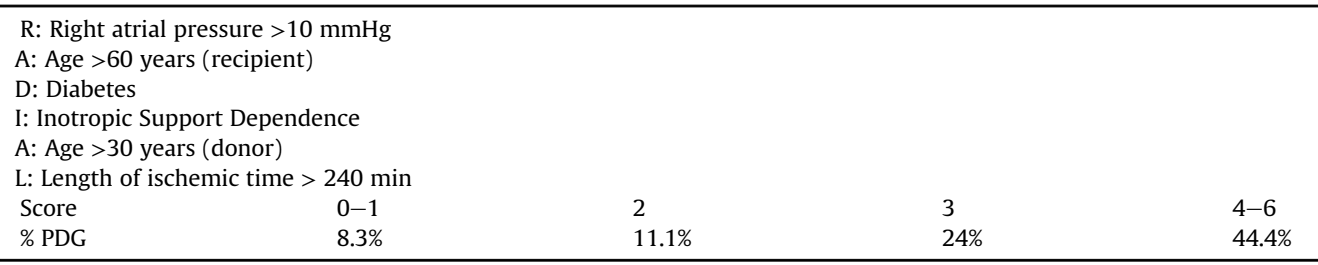

Each present factor accounts for one point in the total score. The score is then used to identify high-risk individuals for primary graft dysfunction, but is less accurate to predict the exact occurrence of primary graft dysfunction in a single patient (PDG primary graft dysfunction).

\section{Table 2}

Classification and severity of primary graft dysfunction.

\begin{tabular}{|c|c|c|}
\hline Class & Severity & Criteria \\
\hline \multirow[t]{4}{*}{ PGD-LV } & Mild & $\begin{array}{l}\mathrm{LVEF} \leq 40 \% \text { by echocardiography, or RAP }>15 \mathrm{mmHg} \text {, PCWP }>20 \mathrm{mmHg} \text {, } \\
\mathrm{Cl}<2.0 \mathrm{~L} / \mathrm{min} / \mathrm{m}^{2} \text { (lasting more than } 1 \mathrm{~h} \text { ) requiring low-dose inotropes }\end{array}$ \\
\hline & Moderate & $\begin{array}{l}\text { I. Has one of the following: } \\
\text { - } \mathrm{LVEF} \leq 40 \% \text {, or RAP }>15 \mathrm{mmHg} \text {, PCWP }>20 \mathrm{mmHg}, \mathrm{CI}<2.0 \mathrm{~L} / \mathrm{min} / \mathrm{m}^{2} \text {, } \\
\text { MAP }<70 \mathrm{mmHg} \text { (lasting more than } 1 \mathrm{~h} \text { ) }\end{array}$ \\
\hline & & $\begin{array}{l}\text { AND } \\
\text { II. Has one of the following: } \\
\text { - High-dose inotropes } \\
\text { - Newly placed IABP }\end{array}$ \\
\hline & Severe & $\begin{array}{l}\text { Dependence on left or biventricular mechanical support } \\
\text { (ECMO, LVAD, BiVAD, or percutaneous LVAD) }\end{array}$ \\
\hline PGD - RV & Not defined & $\begin{array}{l}\text { Requires: RAP }>15 \mathrm{mmHg}, \mathrm{PCWP}<15 \mathrm{mmHg}, \mathrm{CI}<2.0 \mathrm{~L} / \mathrm{min} / \mathrm{m}^{2} \\
\text { and transpulmonary gradient }<15 \mathrm{mmHg} \text { and/or PASP }<50 \mathrm{mmHg} \text { Or need for RVAD }\end{array}$ \\
\hline
\end{tabular}

PGD LV - Primary Graft Dysfunction Left ventricle; PGD RV - Primary Graft Dysfunction Right ventricle; LVEF - left ventricular ejection fraction; RAP - right atrial pressure; PCWP - pulmonary capillary wedge pressure; CI - Cardiac index; IABP - intraaortic balloon pump; ECMO - extracorporeal membrane oxygenation; LVAD - left ventricular assist device; BiVAD - biventricular assist device; PASP - pulmonary artery systolic pressure; RVAD - right ventricular assist device. 
transplantation. The incidence of CAV is $7.8 \%$ at 1 year but then rises to nearly $50 \%$ at 10 years $[3,4,33]$. $\mathrm{CAV}$ is a minor contributor to mortality at $<1$ year after transplantation but dramatically increases to an annual contributor of $>10 \%$ of deaths after the first year (Fig. 2) [3,4]. The occurrence of CAV has not decreased despite advancements in immunosuppressive therapies and better prevention of acute rejection [34]. Risk factors for the development of CAV include male gender, ischemic cardiomyopathy prior to transplant, and re-transplant [4], while statins and mTOR inhibitors are preventative [35].

Because of denervation of the allograft, CAV does not have a clinical presentation similar to nontransplant coronary artery disease, but instead may have atypical symptoms such as exertional dyspnea, gastrointestinal symptoms or may have a severe initial presentation such as heart failure, arrhythmias, or sudden cardiac death. To provide early diagnosis, post-transplant patients undergo screening with coronary angiography starting at the first-year post transplant and annually or biannually thereafter. Angiography is more sensitive for late disease, but the addition of intravascular ultrasound (IVUS) increases the sensitivity for early CAV [36]. Angiographic evidence of CAV increases the relative risk of cardiac events including sudden death and the increased risk of any cardiac-related mortality [36,37].

Proximal CAV is from donor-inherited atherosclerosis and is typically more focal and eccentric. Midand distal CAV is immune-mediated, recipient-acquired, and typically more diffuse and concentric [35]. Presence of arterial inflammation is associated with proliferation of the vasa vasorum and angiogenesis of small peri-arterial vessels around the coronary arteries [38]. Grading of CAV has been defined by the International Society of Heart and Lung Transplantation (ISHLT, Table 3). The treatment of CAV primarily includes modifying immunosuppressive regimens. The use of statins provides not only control of cholesterol levels but also has anti-inflammatory and immunomodulatory benefit. Statins have shown benefits in decreasing short- and long-term rejection, improving survival, limiting the progression of CAV atherosclerosis, and preventing cardiovascular events [39-41]. Such benefits are more pronounced when statins are initiated early [42]; therefore, the ISHLT guidelines recommend use of statins 1-2 weeks after heart transplantation regardless of cholesterol levels [43]. Such recommendations are made despite known interactions of statins with calcineurin inhibitors. Percutaneous coronary intervention ( $\mathrm{PCI}$ ) and coronary artery bypass grafting (CABG) can be used in select patients without diffuse disease but do not lead to improved survival because of the progressive and diffuse nature of CAV [35].

Renal

CKD after heart transplantation is common with up to 50\% of patients suffering from some degree of CKD at year 5, and 6\% requiring dialysis at year 10 (Table 4) [4,44,45]. Risk factors for the development of CKD after heart transplantation include age, female gender, pretransplantation GFR, pretransplant tobacco use, presence of pretransplantation hypertension or diabetes mellitus, ischemic cardiomyopathy prior to transplant, re-transplantation, and postoperative acute kidney insufficiency [4,33,45-48]. Donor demographics do not appear to confer the risk of CKD to transplant recipients, while pretransplant inotrope use and mechanical circulatory support devices may [46]. The risk of developing CKD increases annually after transplantation, and 3.7\% of patients undergo renal transplant by year 10 [4]. Calcineurin inhibitor use is common in the management of the heart transplant recipient, and though calcineurin inhibitors are nephrotoxic agents, there has been conflicting

Table 3

ISHLT grading of cardiac allograft vasculopathy.

\begin{tabular}{|c|c|c|}
\hline Grade & Severity & Definition \\
\hline CAV 0 & Not significant & No detectable angiographic lesion \\
\hline CAV 1 & Mild & $\begin{array}{l}\text { Angiographic LM }<50 \% \text {, or primary vessel with lesion }<70 \% \text {, } \\
\text { or branch stenosis }<70 \% \text {, without allograft dysfunction }\end{array}$ \\
\hline CAV 2 & Moderate & $\begin{array}{l}\text { Angiographic } \mathrm{LM} \geq 50 \% \text {, or primary vessel with lesion } \geq 70 \% \text {, } \\
\text { or branch stenosis } \geq 70 \% \text { in branches of two systems, without allograft dysfunction }\end{array}$ \\
\hline CAV 3 & Severe & $\begin{array}{l}\text { Angiographic } \mathrm{LM} \geq 50 \% \text {, or two or more primary vessels with } \geq 70 \% \text { stenosis, } \\
\text { or branch stenosis } \geq 70 \% \text { in all three branch systems; or CAV } 1 \text { or CAV } 2 \text { with } \\
\text { allograft dysfunction (LVEF } \leq 45 \% \text { or restrictive physiology) }\end{array}$ \\
\hline
\end{tabular}

CAV Cardiac allograft vasculopathy; LM left main; LVEF left ventricular ejection fraction. 
Table 4

Morbidity after heart transplantation.

\begin{tabular}{llll}
\hline Outcome & Within 1 year (\%) & Within 5 years $(\%)$ & Within 10 years $(\%)$ \\
\hline Hypertension & 71 & 91 & $\ldots$ \\
Renal dysfunction & 25 & 51 & 68 \\
Creatinine $(\mathrm{mg} / \mathrm{dl})$ & & & 40 \\
$\leq 2.5($ abnormal) & 17 & 33 & 19 \\
$>2.5$ & 6.1 & 14 & 6.2 \\
Chronic dialysis & 1.7 & 3 & 3.7 \\
Renal transplant & 0.3 & 1.3 & $\ldots$ \\
Hyperlipidemia & 60 & 88 & $\ldots$ \\
Diabetes & 23 & 37 & 48 \\
CAV & 7.8 & 29 & \\
\hline
\end{tabular}

Morbidity after heart transplantation varies at 1-, 5-, and 10-year post-heart transplantation, with increasing rates of hypertension, renal dysfunction, diabetes, and cardiac allograft vasculopathy (CAV - Cardiac Allograft Vasculopathy). Reprinted from $J$ Heart Lung Transplant 35 (10), Lund et al. The Registry of the International Society for Heart and Lung Transplantation: Thirtythird Adult Heart Transplantation Report - 2016: Focus Theme: Primary Diagnostic Indications for Transplant, 1158-1169, 2016, with permission from Elsevier.

evidence that these agents contribute to CKD after heart transplantation [44,46,49,50]. Conversely, these agents are necessary to prevent the rejection of the cardiac allograft. The development of CKD after transplantation is a significant complication, leading to a fourfold increase in mortality $[45,47]$. Recipients that ultimately require dialysis for end-stage renal disease have an even larger increase in mortality than those that do not (56.2\% vs 35.9\%, respectively) [45]. Renal dysfunction contributes little to mortality in the first 5 years after transplantation, but CKD progresses over time, and the contribution of CKD to overall mortality increases after 5 years post-transplantation [3].

\section{Endocrine}

While diabetes mellitus remains a common comorbidity in patients with advanced heart failure undergoing heart transplantation, hyperglycemia due to chronic steroid use may result in a new diagnosis of diabetes post-transplantation in up to $23-39 \%$ of patients in the first 2 years (Table 4) $[4,51-54]$. Age $>50$ years, non-white race, body mass index $>25$, pretransplant ischemic heart disease, recipient CMV-positivity, tobacco use, tacrolimus use, and steroid use are independent risk factors for the development of new onset diabetes [52-54]. Early steroid withdrawal (up to 12 months post heart transplantation), however, may result in less post-transplant diabetes or reversal of post-transplant diabetes $[54,55]$.

The effect of diabetes mellitus on long-term outcomes after heart transplantation remains unknown. Some studies have shown an increase in morbidity and mortality in recipients with diabetes [51,53,56-60], while others have not [44,53,61]. The ISHLT registry demonstrated a $20-40 \%$ increase in 1 - and 5-year mortality in recipients with diabetes, even when carefully selected, and therefore diabetes mellitus with end-organ dysfunction remains a relative contraindication to cardiac transplantation $[1,3,4,57]$. Because of microvascular complications of diabetes mellitus, heart transplant recipients with diabetes may be at the increased risk of CAV, renal dysfunction, stroke, reduced cardiac function, and infection $[56,58,59]$.

\section{Immunologic}

\section{Rejection}

Hyperacute rejection is mediated by preexisting antibodies to allogeneic antigens and occurs immediately after transplantation with rapid graft failure. It is uncommon because of the current bloodand antigen-typing techniques. Acute rejection can be subdivided into cellular or antibody-mediated rejection (AMR) and accounts for $8 \%$ of deaths after heart transplantation [3]. The incidence of any acute rejection in the first year after transplantation is $25 \%$, while the incidence of treated rejection is $13 \%$ because mild cellular rejection may not warrant treatment $[3,4]$. The incidence of any rejection has continued to decrease in the past decade because of improved immunosuppression [4]. 
Acute cellular rejection is characterized by an inflammatory infiltrate on endomyocardial biopsy. The infiltrate is composed of lymphocytes predominantly, while macrophages and eosinophils may also be present. Necrosis of the myocardium may be present and may be a feature of more severe rejection. Endomyocardial biopsies are performed on a routine basis after transplantation because acute rejection is commonly asymptomatic. Acute cellular rejection is graded according to the ISHLT grading system (Table 5) [62]. Acute symptomatic cellular rejection should be treated with high-dose corticosteroids, regardless of ISHLT grade [43]. If hemodynamic compromise is present, antithymocyte antibodies should be administered as well, especially if there is no clinical improvement within 12-24 h of corticosteroid administration. Asymptomatic severe rejection (ISHLT 3R) should be treated with intravenous corticosteroids (and is often managed with cytolytic therapies such as antithymocyte globulin), while asymptomatic moderate rejection (ISHLT 2R) can be treated with oral or intravenous corticosteroids. The maintenance immunosuppressive regimen should be adjusted to prevent subsequent rejection. Follow-up biopsy should be performed 1-2 weeks after treatment for symptomatic and 2-4 weeks after asymptomatic acute cellular rejection [43].

Antibody-mediated rejection has recently been redefined by the ISHLT and should be based on immunopathologic features [63]. Staining for C4d, C3d, and CD68 should be performed in addition to the determination of non-HLA antibodies present on endomyocardial biopsy. Because of nonstandard definitions used in the literature, the exact incidence is unknown, and is therefore reported to be between 3\% and 85\% [63]. Risk factors for the development of AMR include female gender, pretransplant elevated panel reactive antibody, CMV-seropositivity, prior mechanical circulatory support, allosensitization against anti-HLA antibodies, prior treatment with muromonabCD3 and the development of antibodies against mouse monoclonal muromonab-CD3, history of retransplantation, multiparity, and positive T-cell flow cytometry crossmatch [63]. Management of AMR includes intravenous immunoglobulin (IVIg), plasmapheresis, antilymphocyte antibodies, and high-dose corticosteroids for primary therapy. Secondary therapy includes rituximab, bortezomib, and anticomplement antibodies. Maintenance immunosuppression may also be changed, including changing from cyclosporine to tacrolimus or increasing the dose of mycophenolate mofetil $[43,63]$.

\section{Infections}

Infections are a common morbidity after heart transplantation because of the immunosuppressed state and lead to increased mortality. Up to $13.4 \%$ of deaths in the first month after transplantation are attributed to non-CMV infections, with bacterial septicemia being the predominant infection [4]. During the first year after transplantation, mortality from infections remains high (31.3\%), but subsequently declines to approximately $10-13 \%$ per year [4].

Upper and lower respiratory tract infections are common [64] and are important predictors of mortality, representing a significant portion of the post-transplantation mortality. Pulmonary infections occur more frequently during the first 6 months after transplantation $[64,65]$. Some series report that pulmonary infections are the most common cause of mortality in heart transplant patients, with Aspergillus fumigatus being the most common opportunistic pathogen, particularly within the first 3 months [66,67]. The incidence of pneumonia in transplant recipients is $21 \%$, with $75 \%$ of cases occurring in the first 3 months. Most causal agents are opportunistic (60\%) and nosocomial (25\%). The most frequently identified microorganisms are $C M V$, Aspergillus species, and Pneumocystis jirovecii. The described overall mortality rate is $30.8 \%$. The presence of bilateral pulmonary infiltrates and Aspergillus infection are independent risk factors of a poor prognosis [67].

\section{Table 5}

ISHLT standardized acute cellular rejection grading.

\begin{tabular}{lll}
\hline Grade & Severity & Definition \\
\hline Grade 0 R & Not significant & No rejection \\
Grade 1 R & Mild & Interstitial and/or perivascular infiltrate with up to one focus of myocyte damage \\
Grade 2 R & Moderate & Two or more foci of infiltrate with associated myocyte damage \\
Grade 3 R & Severe & Diffuse infiltrate with multifocal myocyte damage \pm edema \pm hemorrhage \pm vasculitis \\
\hline
\end{tabular}




\section{Malignancy}

Malignancy is the fourth most common cause of death at 5 years after transplantation [4]. Up to $28 \%$ of patients will have a malignancy by year 10 after transplantation $[4,33]$. The most common malignancies are skin (18\%) and lymphomas (1.9\%) [4]. Though lymphomas only account for $<2 \%$ of malignancies, they are associated with higher mortality than skin malignancies. Other malignancies account for a combined incidence of $10 \%$ and include prostate, lung, bladder, Kaposi's sarcoma, breast, cervical, colon, and renal cancers [4].

\section{Functional outcomes and quality of life}

Heart transplantation not only provides increased survival but also improves the quality of life and functional ability in transplant recipients. Despite significantly improved functional scores when compared with pretransplant status, many patients report problems in functional areas 1 year post transplantation. A study assessing a large cohort of transplant recipients by measuring Sickness Impact Profile functional scores found that the major problem areas were work (for $90 \%$ of patients), eating (because of dietary restrictions, $87 \%$ ), social interaction (70\%), recreation (63\%), home management (62\%), and ambulation (54\%) [68]. More importantly, this study found that only $26 \%$ of patients were working 1 year after transplant. Additionally, in the group of patients working, 59\% reported healthrelated problems affecting job performance [68]. At 1 year after transplant, predictors of lower functional status are presence of more symptoms, stress, neurologic problems, depression, female sex, older age, and lower left ventricular ejection fraction [68]. In the long term, patient satisfaction improves, with all areas of life rated highly at 5-6 years after heart transplantation. However, patients older than 60 years were more satisfied with their quality of life than younger patients [69].

A study addressing age and gender differences in functional outcomes of heart transplant recipients found that women reported more symptoms (including cardiovascular, gastrointestinal, and dermatologic) and more functional disability (including in ambulation, mobility, self-care, and home management). Older patients reported more disability in ambulation and work. In general, the differences in symptoms and disability were more pronounced by gender than by age [70].

\section{Summary}

The overall outcomes of heart transplantation continue to improve. A considerable progress has been achieved in decreasing early mortality by more refined and effective management of graft failure and dysfunction. However, long-term mortality continues to be affected by progressive CAV, late graft failure, rejection, infectious complications, and issues because of chronic immunosuppression. While the ultimate aims of preventing rejection and finding alternatives to immunosuppression are still elusive, other supportive and therapeutic modalities that promise to help alleviate problems such as graft failure, PGD, and CAV are rapidly evolving. Similar attention is required to improve donor selection and optimal physiological management, donor graft and recipient matching, and graft preservation techniques.

\section{Practice points}

- During the first year, graft failure, infection, and multiorgan failure are the most common causes of mortality.

- In the long term, malignancy, graft failure, cardiac allograft vasculopathy, and infections are the most common causes of mortality.

- Delirium and cerebrovascular events are the most common neurologic complications in the perioperative setting after heart transplant, with pain and depression common in the long term.

- Chronic kidney disease is common after heart transplantation and is associated with increased mortality.

- Up to $39 \%$ of heart transplant recipients develop diabetes mellitus after transplantation.

- Management of PGD is mostly supportive, but early mechanical circulatory support can improve survival. 


\section{Research agenda}

- Prevention and treatment strategies for cardiac allograft vasculopathy

- Optimal immunosuppression strategy

- Prevention of renal dysfunction after heart transplantation

- Understanding the molecular mechanisms of graft damage during PGD and its translation into effective therapies.

- Multicenter trials and mega data assessing effective protocols for PGD with the development of inter-institutional protocols.

- Understand the mechanisms of graft preservation injury to improve organ preservation and transportation methods.

\section{Funding source}

No sponsors contributed funding for this work.

\section{Conflicts of interest}

None of the authors have real or perceived conflicts of interest.

\section{References}

*[1] Mehra MR, Canter CE, Hannan MM, et al. The 2016 International Society for Heart Lung Transplantation listing criteria for heart transplantation: a 10-year update. J Heart Lung Transplant: The Official Publication of the International Society for Heart Transplantation 2016 Jan;35(1):1-23. PubMed PMID: 26776864.

*[2] Lund LH, Edwards LB, Kucheryavaya AY, et al. The registry of the International Society for Heart and Lung Transplantation: thirty-first official adult heart transplant report-2014; focus theme: retransplantation. J Heart Lung Transplant: The Official Publication of the International Society for Heart Transplantation 2014 Oct;33(10):996-1008. PubMed PMID: 25242124.

*[3] Lund LH, Edwards LB, Kucheryavaya AY, et al. The registry of the International Society for Heart and Lung Transplantation: thirty-second official adult heart transplantation Report-2015; focus theme: early graft failure. J Heart Lung Transplant: The Official Publication of the International Society for Heart Transplantation 2015 Oct;34(10):1244-54. PubMed PMID: 26454738.

*[4] Lund LH, Edwards LB, Dipchand AI, et al. The registry of the International Society for Heart and Lung Transplantation: thirty-third adult heart transplantation Report-2016; focus theme: primary diagnostic indications for transplant. J Heart Lung Transplant: The Official Publication of the International Society for Heart Transplantation 2016 Oct;35(10):1158-69. PubMed PMID: 27772668.

[5] Singh TP, Almond C, Givertz MM, et al. Improved survival in heart transplant recipients in the United States: racial differences in era effect. Circ Heart Fail 2011 Mar;4(2):153-60. PubMed PMID: 21228316. Pubmed Central PMCID: 4256951.

*[6] van de Beek D, Kremers W, Daly RC, et al. Effect of neurologic complications on outcome after heart transplant. Archives Neurol 2008 Feb;65(2):226-31. PubMed PMID: 18268192.

[7] Perez-Miralles F, Sanchez-Manso JC, Almenar-Bonet L, et al. Incidence of and risk factors for neurologic complications after heart transplantation. Transplant Proc 2005 Nov;37(9):4067-70. PubMed PMID: 16386628.

[8] Alejaldre A, Delgado-Mederos R, Santos MA, et al. Cerebrovascular complications after heart transplantation. Curr Cardiol Rev 2010 Aug;6(3):214-7. PubMed PMID: 21804780. Pubmed Central PMCID: 2994113.

[9] Patlolla V, Mogulla V, DeNofrio D, et al. Outcomes in patients with symptomatic cerebrovascular disease undergoing heart transplantation. J Am Coll Cardiol 2011 Aug 30;58(10):1036-41. PubMed PMID: 21867839.

[10] Acampa M, Lazzerini PE, Guideri F, et al. Ischemic stroke after heart transplantation. J Stroke 2016 May;18(2):157-68. PubMed PMID: 26915504. Pubmed Central PMCID: 4901943.

*[11] Daneshmand MA, Krishnamoorthy A, Samsky MD, et al. Comparison of 2-year outcomes of extended criteria cardiac transplantation versus destination left ventricular assist device therapy using continuous flow. Am J Cardiol 2015 Aug 15; 116(4):573-9. PubMed PMID: 26092273.

[12] Zierer A, Melby SJ, Voeller RK, et al. Significance of neurologic complications in the modern era of cardiac transplantation. Ann Thorac Surg 2007 May;83(5):1684-90. PubMed PMID: 17462379.

[13] Belvis R, Marti-Fabregas J, Cocho D, et al. Cerebrovascular disease as a complication of cardiac transplantation. Cerebrovasc Dis 2005;19(4):267-71. PubMed PMID: 15731558.

[14] Heroux A, Pamboukian SV. Neurologic aspects of heart transplantation. Handb Clin Neurol 2014;121:1229-36. PubMed PMID: 24365414.

[15] Massaro AR, Dutra AP, Almeida DR, et al. Transcranial Doppler assessment of cerebral blood flow: effect of cardiac transplantation. Neurology 2006 Jan 10;66(1):124-6. PubMed PMID: 16401862.

[16] Bagnato S, Mina C, Sant'Angelo A, et al. Occurrence of neuropathies in patients with severe heart failure before and after heart transplantation. Neurol Sci: Official Journal of the Italian Neurological Society and of the Italian Society of Clinical Neurophysiology 2016 Mar;37(3):393-401. PubMed PMID: 26573590. 
[17] Fletcher SN, Kennedy DD, Ghosh IR, et al. Persistent neuromuscular and neurophysiologic abnormalities in long-term survivors of prolonged critical illness. Crit Care Med 2003 Apr;31(4):1012-6. PubMed PMID: 12682465.

[18] Grandi S, Sirri L, Tossani E, et al. Psychological characterization of demoralization in the setting of heart transplantation. J Clin Psychiatry 2011 May;72(5):648-54. PubMed PMID: 21208590.

[19] Conway A, Schadewaldt V, Clark R, et al. The psychological experiences of adult heart transplant recipients: a systematic review and meta-summary of qualitative findings. Heart Lung: The Journal of Critical Care 2013 Nov-Dec;42(6):449-55. PubMed PMID: 24035493.

[20] Olson TP, Denzer DL, Sinnett WL, et al. Prognostic value of resting pulmonary function in heart failure. Clin Med Insights Circ Respir Pulm Med 2013;7:35-43. PubMed PMID: 24058279. Pubmed Central PMCID: 3771819.

[21] Wright RS, Levine MS, Bellamy PE, et al. Ventilatory and diffusion abnormalities in potential heart transplant recipients. Chest 1990 Oct;98(4):816-20. PubMed PMID: 2209136.

[22] Lizak MK, Zakliczynski M, Jarosz A, et al. The influence of chronic heart failure on pulmonary function tests in patients undergoing orthotopic heart transplantation. Transplant Proc 2009 Oct;41(8):3194-7. PubMed PMID: 19857708.

[23] Al-Rawas OA, Carter R, Stevenson RD, et al. Exercise intolerance following heart transplantation: the role of pulmonary diffusing capacity impairment. Chest 2000 Dec;118(6):1661-70. PubMed PMID: 11115456.

[24] Braith RW, Limacher MC, Mills Jr RM, et al. Exercise-induced hypoxemia in heart transplant recipients. J Am Coll Cardiol 1993 Sep;22(3):768-76. PubMed PMID: 8354811.

[25] Marconi C, Marzorati M. Exercise after heart transplantation. Eur J Appl Physiol 2003 Oct;90(3-4):250-9. PubMed PMID: 13680240.

*[26] Russo MJ, Iribarne A, Hong KN, et al. Factors associated with primary graft failure after heart transplantation. Transplantation 2010 Aug 27;90(4):444-50. PubMed PMID: 20622755

*[27] Kobashigawa J, Zuckermann A, Macdonald P, et al. Report from a consensus conference on primary graft dysfunction after cardiac transplantation. J Heart Lung Transplant: The Official Publication of the International Society for Heart Transplantation 2014 Apr;33(4):327-40. PubMed PMID: 24661451.

[28] Segovia J, Cosio MD, Barcelo JM, et al. RADIAL: a novel primary graft failure risk score in heart transplantation. J Heart Lung Transplant: The Official Publication of the International Society for Heart Transplantation 2011 Jun;30(6):644-51. PubMed PMID: 21470878.

[29] Kittleson MM. Changing role of heart transplantation. Heart Fail Clin 2016 Jul;12(3):411-21. PubMed PMID: 27371517.

[30] Kittleson MM, Patel JK, Moriguchi JD, et al. Heart transplant recipients supported with extracorporeal membrane oxygenation: outcomes from a single-center experience. J Heart Lung Transplant: The Official Publication of the International Society for Heart Transplantation 2011 Nov;30(11):1250-6. PubMed PMID: 21676629.

[31] Listijono DR, Watson A, Pye R, et al. Usefulness of extracorporeal membrane oxygenation for early cardiac allograft dysfunction. J Heart Lung Transplant: The Official Publication of the International Society for Heart Transplantation 2011 Jul;30(7):783-9. PubMed PMID: 21481606.

[32] Takeda K, Li B, Garan AR, et al. Improved outcomes from extracorporeal membrane oxygenation versus ventricular assist device temporary support of primary graft dysfunction in heart transplant. J Heart Lung Transplant: The Official Publication of the International Society for Heart Transplantation 2016 Dec 23;36(6):650-6. PubMed PMID: 28087104.

*[33] Gonzalez-Vilchez F, Arizon JM, Segovia J, et al. Chronic renal dysfunction in maintenance heart transplant patients: the ICEBERG study. Transplant Proc 2014 Jan-Feb;46(1):14-20. PubMed PMID: 24507019.

[34] von Rossum A, Laher I, Choy JC. Immune-mediated vascular injury and dysfunction in transplant arteriosclerosis. Front Immunol 2014;5:684. PubMed PMID: 25628623. Pubmed Central PMCID: 4290675.

[35] Skoric B, Cikes M, Ljubas Macek J, et al. Cardiac allograft vasculopathy: diagnosis, therapy, and prognosis. Croat Med J 2014 Dec;55(6):562-76. PubMed PMID: 25559827. Pubmed Central PMCID: 4295072.

[36] Torres HJ, Merello L, Ramos SA, et al. Prevalence of cardiac allograft vasculopathy assessed with coronary angiography versus coronary vascular ultrasound and virtual histology. Transplant Proc 2011 Jul-Aug;43(6):2318-21. PubMed PMID: 21839263.

[37] Colvin-Adams M, Agnihotri A. Cardiac allograft vasculopathy: current knowledge and future direction. Clin Transplant 2011 Mar-Apr;25(2):175-84. PubMed PMID: 21457328.

[38] Rahmani M, Cruz RP, Granville DJ, et al. Allograft vasculopathy versus atherosclerosis. Circulation Res 2006 Oct 13;99(8): 801-15. PubMed PMID: 17038650.

[39] Sieg A, Weeks P, Krustchinsky L, et al. Statin therapy in cardiac allograft vasculopathy progression in heart transplant patients: does potency matter? Transplant Rev 2016 Jul;30(3):178-86. PubMed PMID: 27079752.

[40] Kobashigawa JA, Katznelson S, Laks H, et al. Effect of pravastatin on outcomes after cardiac transplantation. N Engl J Med 1995 Sep 07:333(10):621-7. PubMed PMID: 7637722.

[41] Kobashigawa JA, Moriguchi JD, Laks H, et al. Ten-year follow-up of a randomized trial of pravastatin in heart transplant patients. J Heart Lung Transplant: The Official Publication of the International Society for Heart Transplantation 2005 Nov;24(11):1736-40. PubMed PMID: 16297773.

[42] Kato T, Tokoro T, Namii Y, et al. Early introduction of HMG-CoA reductase inhibitors could prevent the incidence of transplant coronary artery disease. Transplant Proc 2000 Mar;32(2):331-3. PubMed PMID: 10715431.

[43] Costanzo MR, Dipchand A, Starling R, et al. The International Society of Heart and Lung Transplantation guidelines for the care of heart transplant recipients. J Heart Lung Transplant: The Official Publication of the International Society for Heart Transplantation 2010 Aug;29(8):914-56. PubMed PMID: 20643330.

[44] Janus N, Launay-Vacher V, Sebbag L, et al. Renal insufficiency, mortality, and drug management in heart transplant. Results of the CARIN study. Transpl Int: Official journal of the European Society for Organ Transplantation 2014 Sep; 27(9):931-8. PubMed PMID: 24853579.

[45] Ojo AO, Held PJ, Port FK, et al. Chronic renal failure after transplantation of a nonrenal organ. N Engl J Med 2003 Sep 04; 349(10):931-40. PubMed PMID: 12954741.

[46] Lachance K, White M, de Denus S. Risk factors for chronic renal insufficiency following cardiac transplantation. Ann Transplant 2015 Sep 29;20:576-87. PubMed PMID: 26417876.

[47] Thomas HL, Banner NR, Murphy CL, et al. Incidence, determinants, and outcome of chronic kidney disease after adult heart transplantation in the United Kingdom. Transplantation 2012 Jun 15;93(11):1151-7. PubMed PMID: 22531494. 
[48] Sanchez Lazaro IJ, Almenar Bonet L, Martinez-Dolz L, et al. Effect of hypertension, diabetes, and smoking on development of renal dysfunction after heart transplantation. Transplant Proc 2008 Nov;40(9):3049-50. PubMed PMID: 19010189.

[49] Groetzner J, Kaczmarek I, Schulz U, et al. Mycophenolate and sirolimus as calcineurin inhibitor-free immunosuppression improves renal function better than calcineurin inhibitor-reduction in late cardiac transplant recipients with chronic renal failure. Transplantation 2009 Mar 15;87(5):726-33. PubMed PMID: 19295318.

[50] Manito N, Rabago G, Palomo J, et al. Improvement in chronic renal failure after mycophenolate mofetil introduction and cyclosporine dose reduction: four-year results from a cohort of heart transplant recipients. Transplant Proc 2011 Sep; 43(7):2699-706. PubMed PMID: 21911149.

[51] Saraiva J, Sola E, Prieto D, et al. Diabetes as an outcome predictor after heart transplantation. Interact Cardiovasc Thorac Surg 2011 Nov;13(5):499-504. discussion PubMed PMID: 21835844.

[52] Ye X, Kuo HT, Sampaio MS, et al. Risk factors for development of new-onset diabetes mellitus in adult heart transplant recipients. Transplantation 2010 Jun 27;89(12):1526-32. PubMed PMID: 20431437.

[53] Mogollon Jimenez MV, Sobrino Marquez JM, Arizon Munoz JM, et al. Incidence and importance of de novo diabetes mellitus after heart transplantation. Transplant Proc 2008 Nov;40(9):3053-5. PubMed PMID: 19010191.

[54] Cho MS, Choi HI, Kim IO, et al. The clinical course and outcomes of post-transplantation diabetes mellitus after heart transplantation. J Korean Med Sci 2012 Dec;27(12):1460-7. PubMed PMID: 23255843. Pubmed Central PMCID: 3524423.

[55] Lizak MK, Zakliczynski M, Jarosz A, et al. Early steroid withdrawal-impact on diabetes mellitus and kidney function in heart transplant recipients. Ann Transplant 2011 Oct-Dec;16(4):92-8. PubMed PMID: 22210427.

[56] Higgins J, Pflugfelder PW, Kostuk WJ. Increased morbidity in diabetic cardiac transplant recipients. Can J Cardiol 2009 Apr;25(4):e125-9. PubMed PMID: 19340357. Pubmed Central PMCID: 2706772.

*[57] Mehra MR, Kobashigawa J, Starling R, et al. Listing criteria for heart transplantation: International Society for Heart and Lung Transplantation guidelines for the care of cardiac transplant candidates-2006. J Heart Lung Transplant: The Official Publication of the International Society for Heart Transplantation 2006 Sep;25(9):1024-42. PubMed PMID: 16962464.

[58] Russo MJ, Chen JM, Hong KN, et al. Survival after heart transplantation is not diminished among recipients with uncomplicated diabetes mellitus: an analysis of the United Network of Organ Sharing database. Circulation 2006 Nov 21; 114(21):2280-7. PubMed PMID: 17088463.

[59] Almuti K, Haythe J, Tsao L, et al. Does renal function deteriorate more rapidly in diabetic cardiac transplant recipients? Transplantation 2007 Mar 15;83(5):550-3. PubMed PMID: 17353772.

[60] Meyer SR, Modry DL, Norris CM, et al. Pretransplant diabetes, not donor age, predicts long-term outcomes in cardiac transplantation. J Card Surg 2006 Mar-Apr;21(2):117-24. PubMed PMID: 16492266.

[61] Antonio N, Prieto D, Providencia LA, et al. Diabetes mellitus does not affect one-year outcome after heart transplantation. Rev port cardiol: orgao oficial da Sociedade Portuguesa de Cardiologia = Port J Cardiol: An Official Journal of the Portuguese Society of Cardiology 2010 Feb;29(2):205-20. PubMed PMID: 20545248.

[62] Stewart S, Winters GL, Fishbein MC, et al. Revision of the 1990 working formulation for the standardization of nomenclature in the diagnosis of heart rejection. J Heart Lung Transplant: The Official Publication of the International Society for Heart Transplantation 2005 Nov;24(11):1710-20. PubMed PMID: 16297770.

[63] Colvin MM, Cook JL, Chang P, et al. Antibody-mediated rejection in cardiac transplantation: emerging knowledge in diagnosis and management: a scientific statement from the American Heart Association. Circulation 2015 May 05; 131(18):1608-39. PubMed PMID: 25838326.

[64] van de Beek D, Kremers WK, Del Pozo JL, et al. Effect of infectious diseases on outcome after heart transplant. Mayo Clin Proc 2008 Mar;83(3):304-8. PubMed PMID: 18315996.

[65] Atasever A, Bacakoglu F, Uysal FE, et al. Pulmonary complications in heart transplant recipients. Transplant Proc 2006 Jun;38(5):1530-4. PubMed PMID: 16797351.

[66] Kupeli E, Ulubay G, Akkurt ES, et al. Long-term pulmonary infections in heart transplant recipients. Exp Clin Transplant: Official Journal of the Middle East Society for Organ Transplantation 2015 Apr;13(Suppl 1):356-60. PubMed PMID: 25894190.

[67] Cisneros JM, Munoz P, Torre-Cisneros J, et al. Pneumonia after heart transplantation: a multi-institutional study. Spanish transplantation infection study group. Clin Infect Dis: An Official Publication of the Infectious Diseases Society of America 1998 Aug;27(2):324-31. PubMed PMID: 9709883.

[68] Jalowiec A, Grady KL, White-Williams C. Functional status one year after heart transplant. J Cardiopulm Rehabil Prev 2007 Jan-Feb;27(1):24-32. discussion 3-4. PubMed PMID: 17474641.

[69] Grady KL, Naftel DC, White-Williams C, et al. Predictors of quality of life at 5 to 6 years after heart transplantation. J Heart Lung Transplant: The Official Publication of the International Society for Heart Transplantation 2005 Sep;24(9):1431-9. PubMed PMID: 16143267.

[70] Jalowiec A, Grady KL, White-Williams C. Gender and age differences in symptom distress and functional disability one year after heart transplant surgery. Heart Lung: The Journal of Critical Care 2011 Jan-Feb;40(1):21-30. PubMed PMID: 20561875. Pubmed Central PMCID: 2943992. 